\title{
THE EMOTIONAL STABILITY OF MINERS WITH NYSTAGMUS
}

\author{
BY \\ JUDITH S. LION \\ From the Nuffield Department of Industrial Health, University of Durham (King's College, Newcastle-upon-Tyne)
}

(RECEIVED FOR PUBLICATION APRIL 14, 1958)

The theory has long been held that coal-miners' nystagmus is a psychosomatic disease (Culpin, 1925; Halliday, 1943). The Miners' Nystagmus Committee of the Medical Research Council (1922) originally suggested that the disease was solely the result of deficient illumination but later (1932) concluded that in the treatment of the disease it was chiefly the psychological factors which predominated. Moreover, they pointed out that many of the symptoms of miners' nystagmus, such as photophobia and blepharospasm, occurred where there was no ocular abnormality, and ophthalmologists diagnosed them as hysterical.

Browne (1951) has shown that cats develop nystagmus when kept in the dark, which suggests that lack of illumination is important in producing nystagmus. However, the fact remains that not all miners (or indeed all cats) develop nystagmus and individual psychological differences may well account for this.

Previous attempts to investigate this problem have been based either on subjective assessments by physicians or have been concerned with what is social rather than psychological. It was felt, therefore, that a more objective study would be of value. As a result of the work of Eysenck (1947) and more recently that of Heron (1956), several tests of emotional instability have been devised which have a high measure of reliability. These tests, which have been tried out on many thousands of subjects, have been shown to discriminate between the normal and neurotic, as diagnosed by psychiatrists.

The aim, therefore, of this study is to compare two groups of miners, one group with nystagmus and one without the disease, and to establish by means of a battery of objective tests of emotional instability whether there is a difference between them.

\section{Selection of Groups}

Men with Nystagmus.-Sixty-seven miners were selected (using a random number table) from a list of men who had all been certified by the same physician as having nystagmus. The average age of these men was 53 years. They were all faceworkers and had spent an average of 25 years at the coalface.

Controls.-These men, also randomly selected, were being used as part of a study of pneumoconiosis and their chest radiographs had shown different radiological categories. All the men in both groups worked in the Durham coal field. In order that there should be no bias in the group, the number of men in each radiological category was matched against the frequency distribution of radiological categories in that coal field (McCallum, Browne, and Campbell, 1955). Later an analysis of variance revealed no significant difference between any of the radiological categories on any of the tests.

Seventy-four men out of a possible 101 attended. Seven were rejected as they were unable to perform one of the tests (leg persistence) due to some physical disability. The relatively large number of men who did not attend when requested was due to their not being compensated for loss of shifts, and indeed many of those who did come lost earnings. It was realized that there might be some bias due to self-selection on the part of the men, but a comparison of those men who came on receiving the first letter and those who came only after two or three letters showed no significant difference on any of the tests. The average age of the 67 men who formed the control group was 55 years and they had spent an average of 30 years working at the coalface. All the men were tested at the Nuffield Department of Industrial Health.

\section{The Tests}

A small battery of tests taking 30 to 40 minutes to administer was used.

Two-part Personality Inventory (Heron, 1956).-This, the chief test used, is a questionnaire test consisting of 74 statements concerning physical health, so giving the impression of being an health inventory. The score is based on 18 of these items considered to reveal emotional instability (or neuroticism) when scored in the appropriate direction. In the original inventory there are 20 significant items but owing to the close resemblance of two of these to the symptoms of nystagmus it was decided to omit them from the test. The omitted phrases 
were "My eyesight is sometimes blurred" and "I have no particular physical or health problems".

This test has been validated on more than 1,600 people and has a misclassification rate of only $13 \%$. This means that 87 out of 100 patients diagnosed as neurotic by a psychiatrist would be likely to obtain neurotic scores on this test.

The second part (Heron II) gives a score of sociability dependent on 12 of 36 items.

The remaining tests were as follows:-

Food Aversions (Wallen, 1945). - This is scored as the number of aversions recorded from a list of 24 items of food. Wallen has shown that neurotics generally record a significantly larger number of aversions than others.

Annoyances (Bennett, 1945). - This test records the number of items which the subject chooses as annoying him from a list of 60 possible annoyances.

Hand Persistence (Eysenck, 1947).-This test records the number of seconds the subject can maintain his grip on a hand dynamometer at two-thirds of his maximum grip. The score is the best of two trials, once with each hand. Neurotics have been shown to have less persistence than others.

Leg Persistence (Eysenck, 1947). - This test is a measure of the number of seconds a subject while seated can hold his right leg fully extended at a given distance above a chair. As with hand persistence neurotics are said to have less persistence than others.

Fluency (Eysenck, 1947).-The subject is asked to name as many " round objects" as he can in one minute. Neurotics tend to be less fluent than others.

\section{Results}

Table 1 shows the mean scores for both groups on the seven tests with the appropriate levels of significance. On four out of six tests of emotional instability the men with nystagmus obtained significantly more neurotic responses than the controls, and all were in the expected direction.

TABLE 1

COMPARISON OF MEAN SCORES BETWEEN MEN WITH NYSTAGMUS AND CONTROLS

\begin{tabular}{|c|c|c|c|c|}
\hline Test & \begin{tabular}{|c|} 
Mean Score \\
of Men with \\
Nystagmus \\
$(\mathbf{N}=67)$
\end{tabular} & $\begin{array}{c}\text { Mean Score } \\
\text { of Control } \\
\text { Miners } \\
(\mathbf{N}=67)\end{array}$ & $\begin{array}{c}{ }^{t} \\
132 \text { d.f.) }\end{array}$ & $\begin{array}{l}\text { Level of } \\
\text { Signifi- } \\
\text { cance }\end{array}$ \\
\hline $\begin{array}{l}\text { Heron I- } \\
\text { emotional } \\
\text { instability }\end{array}$ & $9 \cdot 63$ & $7 \cdot 81$ & 3.02 & $P<0.01$ \\
\hline $\begin{array}{l}\text { Annoyances } \\
\text { Food aversions } \\
\text { Hand persistence } \\
\text { Leg persistence } \\
\text { Fluency }\end{array}$ & $\begin{array}{r}39 \cdot 93 \\
5 \cdot 85 \\
46 \cdot 67 \\
38 \cdot 43 \\
7 \cdot 15\end{array}$ & $\begin{array}{r}37 \cdot 08 \\
4 \cdot 51 \\
57 \cdot 49 \\
60 \cdot 36 \\
7 \cdot 18\end{array}$ & $\begin{array}{l}1.07 \\
2.24 \\
2.28 \\
2.80 \\
0.06\end{array}$ & $\begin{aligned} & \text { n.s. } \\
& P<0.05 \\
& P<0.05 \\
& P<0.01 \\
& \text { n.s. }\end{aligned}$ \\
\hline $\begin{array}{l}\text { Heron II- } \\
\text { unsociability }\end{array}$ & 6.46 & 5.91 & $1 \cdot 26$ & n.s. \\
\hline
\end{tabular}

On Heron I, the main test of emotional instability, Student's $t$ test (132 d.f.) revealed a significant difference $(P<0.01)$. Food aversions and hand

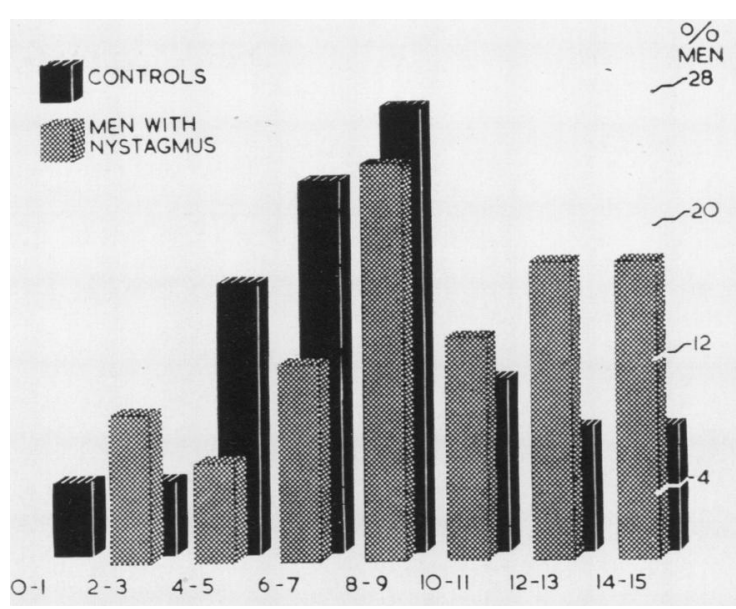

FIG. 1.-Histogram of results of instability test (Heron I) in subjects and controls.

persistence discriminated at the 0.05 level of significance and leg persistence at the 0.01 level.

No significant difference appeared on the annoyances and fluency tests, and this was also true of Heron II, the test of sociability. (It is intended to show in a further paper that the two former tests when included in this battery have very small loadings on a factor of emotional instability.)

Fig. 1 demonstrates the difference between the two groups on Heron I, showing the higher percentage of men with nystagmus at the high scores and the greater percentage of controls at the low scores. Heron considers those with scores of 0 to 7 as " probably well adjusted", scores of 8 and 9 as "doubtful", and over 10 as "probably maladjusted ". In a parallel investigation on emotional instability in underground workers the present author found that miners obtained significantly higher scores on Heron I than workers in another industry, a finding which is consistent with that of Heron and Braithwaite (1953). This explains the relatively high scores obtained by the control group.

TABLE 2

COMPARISON OF MEAN SCORES ON HERON I FOR THREE GRADES OF NYSTAGMUS

\begin{tabular}{c|c|c}
\hline Grades & Number of Men & Mean Score \\
\hline 1 (Mild) & 28 & $9 \cdot 14$ \\
2 (Moderate) & 25 & $10 \cdot 12$ \\
3 (Severe) & 14 & $10 \cdot 14$ \\
\hline
\end{tabular}

Severity of the disease was rated by the certifying physician who had no knowledge of the scores obtained. It will be seen from Table 2 that on Heron I the difference between the mean scores of the three groups is small, and an analysis of variance disclosed no significant difference, i.e., there was no 
concomitant rise in degree of emotional instability with severity.

TABLE 3

LACK OF RELATIONSHIP BETWEEN DURATION OF NYSTAGMUS AND EMOTIONAL INSTABILITY ON HERON TEST I

\begin{tabular}{l|c|c|c|c|c}
\hline & \multicolumn{4}{|c}{ Duration of Nystagmus in Years } \\
\hline & $0-4$ & $5-6$ & $7-8$ & $9-10$ & 11 and over \\
\hline $\begin{array}{l}\text { Number of men } \\
\text { Mean score (Heron I) }\end{array}$ & 6 & 18 & 23 & 9 & 11 \\
\hline
\end{tabular}

There was no evidence of any relationship (see Table 3 ) between emotional instability and duration of the disease.

\section{Discussion}

The majority of these tests of emotional instability have shown a significant difference between the two groups, thereby suggesting that men with nystagmus are more emotionally unstable than men without the disease. It should be stressed that this is the first time a study of the disease has been made using carefully standardized tests. All the findings have been based on objective tests and the results confirm the opinion that psychological factors play an important part in the disease.

The results of Heron's test part II (see Table 1), which shows that there is no difference in sociability between miners with nystagmus and controls, agrees with the findings of Browne and Beck (1954). But, whereas they concluded that there was no difference at all between the two groups, it appears that while being as sociable as the controls, men with nystagmus do show other psychological differences.

However, a basic problem still remains: Which appears first, the nystagmus or the emotional instability ? Is it the case, as Culpin (1925) suggested, that the nystagmus is of purely physical origin and itself precipitates a neurosis, or does the neurotic personality predispose a miner to develop the disease ?

Dorothy Campbell (1948) has suggested that the worry and unemployment resulting from nystagmus may encourage the development of neurosis. But, in this study, which was made in a time of almost full employment in the pits, only six of the 67 men with nystagmus were in fact unemployed and therefore the high scores obtained cannot be attributed to the stress of unemployment.

However, it should be pointed out that only two of the men with nystagmus had returned to their original jobs at the coalface, the remainder being employed in surface work at which they were earning approximately half their previous wages. It would be interesting to compare a group of disabled men from another industry, who were similarly earning much less than their original income, and see whether they obtained high emotional instability scores. This would indicate to what extent the instability is caused by the financial stress resulting from nystagmus or indeed any other disease.

The only way to solve the basic problem of which comes first would be a long-term and large-scale investigation in which all men entering the pit would be given these tests, their scores recorded, and several years later an analysis made of the scores of those men who subsequently developed the disease. In this way it should be possible to determine whether the nystagmus superimposed on a latent emotional instability precipitates a neurotic crisis, or if lack of stability is a factor in causing nystagmus.

With greater improvement in lighting conditions in the pits the incidence of nystagmus is declining, nevertheless, the problem still remains as to why some men develop the disease and others do not.

\section{Summary}

Sixty-seven men suffering from coal-miners' nystagmus and the same number of control miners were compared on a battery of objective tests of emotional instability.

On four out of six tests the men with nystagmus scored significantly more neurotic responses than the controls. All six tests showed a difference in the expected direction between the two groups. It was found that the men with nystagmus were not less sociable than men without the disease. Neither the severity of the disease nor its duration correlated with emotional instability.

This study confirms the view that men with nystagmus are more emotionally unstable than men without the disease.

I wish to thank Professor R. C. Browne under whose helpful guidance the work was carried out; Professor F. V. Smith for his advice; Dr. Alastair Heron for advice and the use of his inventory: Mr. N. Loveless for his many helpful suggestions; Mr. D. Newell for statistical advice; Dr. G. L. Leathart for providing the control group, and Mrs. D. Weightman for assistance with the calculations and tables.

\section{REFERENCES}

Bennett, E. (1945). Brit. J. med. Psychol., 20, 271. Browne, R. C. (1951). Lancet, 1, 721 Cand Beck, I. F. (1954). Brit. med. J., 1, 1176 Campbell, D. A. (1948). Brit. J. Ophthal., 4, 193.

Culpin, M. (1925). Ibid., 11, 564.

Eysenck, H. J. (1947). Dimensions of Personality. Kegan Paul, London.

Halliday, J. L. (1943). Psychomat. Med., 5, 71.

Heron, A. (1956). Brit. J. Psychol., 47, 243.

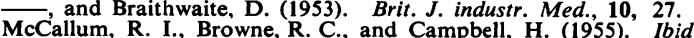
$12,279$.

Miners' Nystagmus Committee (1922). Spec. Rep. med. Res. Coun. (Lond.) No. 65 .

(1932. Ibid. No. 176

Wallen, R. (1945). J. abnorm. soc. Psychol., 40, 271. 